\title{
GÉNEROS Y SEXUALIDADES, FEMINIDADES Y MASCULINIDADES EN ANCLAJES $^{1}$
}

\section{Rafael M. Mérida Jiménez}

Universitat de Lleida

España

rafaelmanuel.merida@udl.cat

Orcid: 0000-0003-0854-2309

Fecha de recepción: 23/06/202 I | Fecha de aceptación: 05/07/202 |

Resumen: Anclajes no es una revista de estudios sobre las mujeres, los géneros o las sexualidades, pero se constata una presencia de estas temáticas que refleja la evolución misma de una línea de investigación poco habitual en las revistas de Humanidades hace unas décadas.

Palabras clave: estudios de género; literatura argentina; crítica literaria; siglo XXI.

\section{Genders and sexualities, feminities and masculinities in Anclajes}

Abstract: Anclajes is not a journal dedicated to studies on women, genders or sexualities. However, the presence of articles dealing with these issues reflects the evolution of a line of research that was unusual in Humanities journals a few decades ago.

Keywords: gender studies; Argentine literature; literary criticism; XXI century.

\section{Gêneros e sexualidades, feminidades e masculinidades em Anclajes}

Resumo: Anclajes não é um periódico de estudos sobre mulheres, gêneros ou sexualidades, mas há uma presença desses temas que refletem a própria evolução de uma linha de pesquisa inusitada em periódicos de Humanidades algumas décadas atrás.

Palavras chave: estudos de género; Literatura argentina; Crítica literária; Século XXI.

1 Este trabajo forma parte del proyecto de investigación "Memorias de las masculinidades disidentes en España e Hispanoamérica" (PID2019-106083GB-I00) del Ministerio de Ciencia e Innovación (Gobierno de España) y se ha desarrollado en el seno del GRC 2017 SGR 588. 
$\left\{\begin{array}{l}\text { nclajes, la revista científica vinculada al Instituto de Investiga- } \\ \text { ciones Literarias y Discursivas de la Universidad Nacional de La } \\ \text { Pampa, cumple veinticinco ańos. Estas bodas de plata entre el }\end{array}\right.$ equipo que la dirige y edita y su público lector merecen ser celebradas y felicitadas. Mi enhorabuena sincera, pues no dudo de que se trata de una efeméride que augura una feliz continuidad, muy en especial a sus directores, Graciela Salto y José J. Maristany, quienes han trabajado para que este aniversario luzca, a pesar de las terribles condiciones que nos afectan a escala mundial a causa de la pandemia. Mucha salud, también, y muchas más alegrías como esta.

Quienes colaboramos en el más sencillo comité de redacción o en el más encumbrado comité científico de cualquier revista académica que pretenda convertirse en un sólido referente para la comunidad universitaria sabemos mucho de las energías y de las horas que requiere su mera existencia cotidiana. En la actualidad, además, muchas exigencias de calidad externa propician que el volumen de trabajo se haya multiplicado, para bien y para mal. En cualquier caso, una sencilla revisión del sitio de internet de Anclajes confirma que la labor realizada es espléndida desde esta perspectiva: su presencia en muy diversos directorios y catálogos, sistemas de indización, bases de datos y portales internacionales resulta contrastadamente admirable. Y ese trabajo poco vistoso, en ocasiones muy enojoso, brinda la medida de su importancia en la actualidad. Mi agradecimiento va destinado también a los consejos editores y de redacción, a sus secretarias, a las responsables de reseñas y dosieres, de traducción, difusión y edición, así como a los numerosos evaluadores externos, impagables.

Pero este esfuerzo, tan relevante a la altura de esta tercera década del siglo $\mathrm{XXI}$, se antoja igualmente el resultado de un empeńo que viene de antiguo -de hace, en definitiva y al menos, 25 años- y que también se percibe en una cuestión no menos importante, como es la relacionada con los contenidos. Parecerá una obviedad, pero no lo es tanto si consideramos que la importancia de una revista quizá debiera medirse simultáneamente por elementos inmateriales, como, por ejemplo, el prestigio acumulado y la capacidad de diálogo con las áreas de conocimiento, las teorías y las metodologías por las que transita y que configuran el horizonte de expectativas de nuestra experiencia como lectores/as.

En el caso de Anclajes, nos encontramos ante una publicación periódica con una voluntad envidiablemente omnicomprensiva: nada del universo literario le resulta ajeno. Esa virtud, en un cosmos como el nuestro que tiende hacia la híper-especialización, constituye también una trampa que toda revista que se precie debe sortear. Lo logra muy bien el equipo si efectuamos un recorrido amplio, como el que me invitan a realizar su directora y su co-director. Anclajes no es una revista de estudios sobre las mujeres, los géneros o las sexualidades, pero a lo largo de estos años constatamos una presencia de estas temáticas que refleja la evolución misma de una línea de investigación poco habitual en las revistas de Humanidades hace unas décadas, aunque hoy nos parezca imposible o inaceptable. Este cambio de paradigma se debe, claro está, a la irrupción del 
feminismo en nuestras universidades, a un lado y a otro del océano; también a sus transformaciones y adaptaciones, como las propiciadas por las teorías queer o los estudios sobre las masculinidades, por mencionar solo dos ejemplos que me resultan cercanos.

Hoy por hoy, creo que estaremos de acuerdo en que hablar de un territorio como el de "los géneros, los cuerpos y las subjetividades disidentes" vinculado a los estudios literarios implica un tipo de bagaje, mezcla de generosidad y ambición, y una curiosidad intelectual de los que dan sobradas muestras tantos y tantos números de Anclajes. Desde las aportaciones de Raquel Miranda y Dayle Seidenspinner-Núñez sobre el Libro de buen amor y el Corbacho en el volumen inaugural, en 1997, hasta el dosier de 2020 consagrado a las representaciones de la violencia de género en las producciones culturales latinoamericanas actuales, editado por Tatiana Navallo y Ainhoa Vásquez Mejías, nos encontramos ante una variada gama de marcos cronológicos, herramientas críticas, textualidades y procedencias que potencian la ductilidad: Anclajes es una revista argentina pero no solo sobre literatura argentina y sus colaboradores proceden de centros de las más diversas latitudes. Este es un gran acierto, en especial cuando nos centramos en los estudios de género, pues su evolución ha conocido diversas centralidades y periferias, temáticas y geográficas, a lo largo de las últimas décadas.

Esto no sería así, tal vez por razones perogrullescas, si creyéramos falazmente que los estudios de género se limitan a los estudios sobre las representaciones literarias femeninas o sobre las escrituras de las mujeres. Anclajes ha brindado abundantes muestras de su interés por las investigaciones en torno a autoras argentinas, hispanoamericanas y españolas: Carmen Lugo Filippi y Ana Lydia Vega (2003), Angélica Gorodischer (2005), Silvina Ocampo (2008), Griselda Gambaro (2015), Ana Rosetti y Almudena Grandes (2017), Emma Barrandeguy y Olga Merino (2018), entre muchas otras, o a las creadoras que recupera el dossier consagrado a las escritoras latinoamericanas y caribeńas entre $1870 \mathrm{y}$ 1940 (2017), preparado por Lucía Stecher y Lucía Cisterna, en cuya presentación se constataba el giro hacia el archivo de los acechos recientes:

Los archivos permiten tanto recuperar voces olvidadas, como completar y enriquecer el conocimiento sobre la obra de escritoras ya visibilizadas por la crítica precedente. Por otra parte, la crítica contemporánea se esfuerza también por releer y recontextualizar la obra de autoras que, si bien ya tienen un lugar en el canon, tienden a ser leídas de forma unidimensional y estereotipada. Es el caso, por citar un ejemplo conocido, de lo que ocurrió en Chile con Gabriela Mistral: fue necesario estudiar nuevamente su obra para dar cuenta de su fuerza, complejidad y carácter subversivo. Por otra parte, el trabajo de archivo ha permitido no solo recuperar textos y autoras perdidas, sino también dar cuenta de los vínculos e intercambios entre escritoras, que configuraron redes que ahora podemos describir en forma cada vez más compleja².

2 Stecher, Lucía. "Intervenciones públicas, configuraciones íntimas: escritoras latinoamericanas y caribeñas entre 1870 y $1940 "$ ". Anclajes, vol. XXI, n. ${ }^{\circ} 3$, setiembre-diciembre 2017, pp. 1-5 (ahora p. 3), https://doig.org/10.19137/anclajes-2017-2131. 
Pero los estudios de género no se limitan a este universo indispensable y lentamente reconocido, sino además a tantas y tantas autorías otras, que atentan contra binarismos improductivos, como muestran las aportaciones publicadas sobre Pedro Lemebel y Manuel Puig (2006), Néstor Perlongher (2012) o Guillermo Saccomanno (2014), por citar solo algunas. En este sentido, Anclajes ha acometido una revisión implícita del canon heterosexista, en especial de las letras sudamericanas, de la mano de apuestas como la del dosier coordinado por Ángeles Mateo del Pino (2019), ofreciendo "lecturas somatopolíticas" de las "multitudes raras y tullidas (queer/cuir-crip)" preteridas, o la del gestado por Jorge Luis Peralta (2018), en torno a masculinidades y diversidad sexual, ambos de clara proyección internacional.

En este último se incluyó un "cuaderno bibliográfico" modélico preparado por Santiago Joaquín Insausti y el propio Peralta -que bien podría ser modelo a imitar en futuros dosieres- en donde advertimos una apuesta de indudable calado:

Los estudios sobre masculinidades constituyen un campo en pleno desarrollo en el contexto académico argentino. El objetivo de este cuaderno es trazar un breve estado de la cuestión en torno a estos estudios, particularmente en su articulación con investigaciones sobre diversidad sexual, señalando debates significativos, así como líneas de trabajo desarrolladas y pendientes. El repertorio bibliográfico recoge y describe algunas de las principales aportaciones en ambos campos, organizadas en dos grandes áreas disciplinares: estudios históricos, sociológicos y antropológicos, por un lado, y estudios literarios, cinematográficos y culturales, por otro ${ }^{3}$.

Es decir, Anclajes nos ha ofrecido una utilísima herramienta como esta (y lo planteo a título metafórico) que informa sobre una encrucijada interdisciplinaria de alto voltaje para el mapa que vengo radiografiando y que alienta futuros debates. No solo en Argentina, pues se irradia sobre diferentes cartografías.

Sin temor a equivocarme -pues a la vista está-, soy de la opinión de que Anclajes ha sido una revista plural y receptiva, menos anclada de lo que su título sugiere a unas prácticas críticas miopes y muy atenta a propuestas novedosas en el ámbito hispánico. La circunstancia que favorece que todo ese arsenal de conocimiento se encuentre disponible en la red me exime de la obligación de resumir (o de cortar y pegar) sus contenidos. Quisiera añadir, además, que junto a los dosieres y artículos que he ido apuntando -y la lista podría ampliarse-, también resulta muy estimulante la sección de reseñas, pues ha esbozado de forma acertada algunos de los rumbos y tumbos de las investigaciones sobre las mujeres, los géneros y las sexualidades de las últimas décadas.

3 Insausti, Santiago Joaquín y Jorge Luis Peralta. "Cuaderno bibliográfico: estudios sobre masculinidades y diversidad sexual en Argentina". Anclajes, vol. XXII, n. ${ }^{\circ}$ 3, setiembre-diciembre 2018, pp. 91-117 (ahora p. 91), https://doi.org/10.19137/anclajes-2018-2238. 
Reitero, en consecuencia, mi agradecimiento y estima por una revista de la categoría de Anclajes. Toda mi admiración hacia el equipo y hacia quienes han colaborado para convertir un sueńo académico, alejado de ciertas rutas acomodaticias, en una realidad cuyo interés trasciende fronteras, también en lo que atañe a los estudios sobre las mujeres y los géneros, los cuerpos y las subjetividades disidentes. ¡Larga vida! 